\title{
Hanging-related injury in Pietermaritzburg, South Africa
}

\author{
J J P Buitendag, ${ }^{1}$ MB ChB, MMedSci, H Dip Surg; A Ras, ${ }^{2}$ MB ChB; V Y Kong, ${ }^{3}$ MB ChB, ChM, MSc, PhD, MRCS (Ed); \\ R D Weale, ${ }^{3}$ MBBS; J Blodgett, ${ }^{4}$ BSc, MSc; J L Bruce, ${ }^{2}$ MB ChB, FCS (SA); D L Clarke, ${ }^{2,3}$ MB ChB, MPhil, MBA, PhD, FCS (SA); \\ G L Laing, ${ }^{2}$ MB ChB, MSc, FCS (SA), Cert Trauma Surgery (SA), PhD
}

\author{
${ }^{1}$ Department of Surgery, Tygerberg Hospital and Faculty of Medicine and Health Sciences, Stellenbosch University, Cape Town, South Africa \\ ${ }^{2}$ Pietermaritzburg Metropolitan Trauma Service, Department of Surgery, College of Health Sciences, University of KwaZulu-Natal, Durban, South Africa \\ ${ }^{3}$ Department of Surgery, Faculty of Health Sciences, University of the Witwatersrand, Johannesburg, South Africa \\ ${ }^{4}$ Department of Surgery, Wessex Deanery, Winchester, UK \\ ${ }^{5}$ MRC Unit for Lifelong Health and Ageing, University College London, UK
}

Corresponding author: J J P Buitendag (johan_buitendag@yahoo.com)

\begin{abstract}
Background. Hanging is a common form of self-harm, and emergency care physicians will not infrequently be called upon to manage a survivor. Despite the relative frequency of the injury, there is a paucity of literature on the topic and the spectrum and incidence of associated injuries are poorly described.

Objectives. To review experience with management of victims of hanging at a major trauma centre in South Africa.

Methods. All patients treated by the Pietermaritzburg Metropolitan Trauma Service following a hanging incident between December 2012 and December 2018 were identified from the Hybrid Electronic Medical Registry. Basic demographics were recorded, and the management and outcome of each patient were noted.

Results. During the 6-year period under review, a total of 154 patients were seen following a hanging incident. The mean age was 29.4 years. There were 24 females (15.6\%) and 130 males (84.4\%). The vast majority $(n=150 ; 97.5 \%)$ had attempted suicide, and only 4 hangings (2.5\%) were accidental. A total of 92 patients $(60.9 \%)$ had consumed alcohol prior to the incident. There were 23 patients with a Glasgow Coma Score (GCS) $<9$ (severe traumatic brain injury (TBI)), 14 with a GCS of $9-12$ (moderate TBI) and 117 with a GCS $>12$ (mild TBI). A total of 7 patients $(4.5 \%)$ required intensive care unit admission, and $25(16.2 \%)$ required intubation. The following extracranial injuries were documented on computed tomography scans: hyoid bone fractures $(n=2)$, cervical spine fracture $(n=10)$, mandible fracture $(n=4)$ and oesophageal injury $(n=1)$. Intracranial pathology was evident on $27.0 \%$ of scans, with the most common finding being global cerebral ischaemia. The mortality rate was $2.5 \%(4 / 154)$.

Conclusions. Hanging is a common mechanism of self-harm. It is associated with significant injuries and mortality. The acute management of hanging should focus on airway protection followed by detailed imaging of the head and neck. Further work must attempt to include mortuary data on hanging.
\end{abstract}

S Afr Med J 2020;110(5):400-402. https://doi.org/10.7196/SAMJ.2020.v110i5.13381

Hanging is a common form of self-harm, and emergency care physicians will not infrequently be called upon to manage a survivor. ${ }^{[1-4]}$ Despite the relative frequency of the injury, there is a paucity of literature on the topic and the spectrum and incidence of associated injuries are poorly described. Our current algorithm for the management of this injury is based on the resuscitation protocols of the Advanced Trauma Life Support (ATLS) Course, which essentially emphasise maintenance of an adequate airway while ensuring that the cervical spine is immobilised and protected. Once this has been achieved, all hanging victims have a contrast-enhanced computed tomography (CT) scan of the head and neck to exclude major intracranial lesions and assess the cervical spine, aerodigestive tract and carotid arteries. Many of the potential injuries to these structures are occult in that they are difficult to detect clinically and potentially serious. Blunt pressure on the carotid vessels may result in the formation of an intimal tear, creating a highly thrombogenic surface in the carotid vessel that may result in a cerebral embolus or complete occlusion of the carotid vessel. This injury may have significant sequelae if undetected and untreated. ${ }^{[1-4]}$

\section{Objectives}

In the light of the above, we set out to review our experience with the management of hanging victims, to establish the yield from contrast
CT scans of the head and neck in these patients, and to compare our findings with the international literature.

\section{Methods \\ Clinical setting}

The study was undertaken at the Pietermaritzburg Metropolitan Trauma Service (PMTS), South Africa. The PMTS provides definitive trauma care to the city of Pietermaritzburg, the capital of KwaZulu-Natal (KZN) Province, and tertiary trauma care to western KZN, with a total catchment population of $>3$ million people. The PMTS maintains a regional trauma registry, the Hybrid Electronic Medical Registry (HEMR). All patients who present to our trauma centre are prospectively entered into the database, and the information recorded includes details regarding injury mechanism, operative intervention, patient progress and clinical outcomes.

Ethics approval for the maintenance of the HEMR has been formally endorsed by the Biomedical Research Ethics Committee of the University of KwaZulu-Natal (ref. no. BCA221/13).

\section{Management of hanging}

All patients presenting to the PMTS are managed according to ATLS principles. The airway is secured while maintaining inline stabilisation of the cervical spine. If a patient is unable to protect 
his/her airway because of a low level of consciousness or ongoing swelling of the neck, intubation is required. All patients who survive a hanging attempt have a contrast-enhanced CT scan of the head and neck to exclude intracranial pathology, as well as cervical spine, aerodigestive tract and carotid artery injury.

\section{The study}

A retrospective review was conducted for the 6-year period December 2012 - December 2018 and included all patients who presented to the PMTS following a hanging incident, identified from the HEMR. Basic demographic details including age and gender were reviewed. Specific information was sought from prehospital emergency medical service documentation in relation to where the incident took place, transportation time and time of arrival at our centre. The presenting physiological values of each patient were reviewed. The yield of contrast-enhanced CT scans in terms of injuries to the cervical spine, the aerodigestive tract and the vasculature of the neck was reviewed. Further clinical information reviewed included the body regions injured, as well as operative interventions, the need for intensive care unit (ICU) admission, morbidity and mortality.

\section{Results}

\section{Demographics}

During the 5-year period under review, a total of 154 patients were seen following a hanging incident. The mean age was 29.4 years. There were 24 females (15.6\%) and 130 males (84.4\%). The vast majority $(n=150 ; 97.5 \%)$ had attempted suicide, and only 4 hangings (2.5\%) were accidental. The prevalence of comorbidities was as follows: $\operatorname{HIV}(n=26 ; 16.9 \%)$, psychiatric illness $(n=17 ; 11.2 \%)$, epilepsy $(n=4 ; 2 \%)$, diabetes $(n=2 ; 1.3 \%)$ and hypertension $(n=1$; $0.6 \%)$. A total of 92 patients $(60.9 \%)$ had consumed alcohol just prior to the incident.

\section{Admission physiological values}

There were 23 (14.9\%) patients with a Glasgow Coma Score (GCS) $<9$ (severe traumatic brain injury (TBI)), 14 (9.1\%) with a GCS of $9-12$ (moderate TBI) and 117 (76.0\%) with a GCS >12 (mild TBI). The presenting physiological values are summarised in Table 1 . A total of 84 patients (54.5\%) were brought in with a hard cervical collar in situ.

\section{External injuries and clinical findings}

In $59.0 \%$ of patients there were abrasions to the neck, $41.0 \%$ had an altered GCS on presentation, and $8.0 \%$ had signs of thoracic pathology which included rib fractures, chest wall abrasions and signs of impaired or altered air entry. Soft signs of vascular injury were present on clinical examination in $2.0 \%$ of patients. Lacerations and extremity injuries were present in $2.0 \%$.

\section{Outcome}

The mortality rate was $4 / 154(2.5 \%)$.

\section{Injuries identified on CT scan}

The following extracranial injuries were documented on CT scan: hyoid bone fractures $(n=2 ; 1.3 \%)$, cervical spine fracture $(n=10$; $6.4 \%)$, mandible fracture $(n=4 ; 2.5 \%)$ and oesophageal injury $(n=1$; $0.6 \%)$. Intracranial pathology was identified in $27.0 \%$ of CT scans, with the commonest finding being global cerebral ischaemia.

\section{Interventions}

A total of 7 patients (4.5\%) required ICU admission, and 25 (16.2\%) required intubation.

\begin{tabular}{|c|c|}
\hline Parameter & Mean (SD) \\
\hline $\mathrm{PO}_{2}(\mathrm{KPa})$ & $16(12.32)$ \\
\hline HGT (g/dL) & $8.3(2.82)$ \\
\hline $\mathrm{Hb}(\mathrm{g} / \mathrm{dL})$ & $13.1(2.06)$ \\
\hline Lactate $(\mathrm{mmol} / \mathrm{L})$ & $4.1(3.57)$ \\
\hline $\mathrm{CO}_{2}(\mathrm{kPa})$ & $7.1(5.88)$ \\
\hline $\mathrm{pH}$ & $7.4(0.15)$ \\
\hline $\mathrm{HCO}_{3}(\mathrm{mmol} / \mathrm{L})$ & $22.8(5.02)$ \\
\hline $\mathrm{BE}(\mathrm{mmol} / \mathrm{L})$ & $-2.8(6.47)$ \\
\hline SATS (\%) & $95(13.97)$ \\
\hline SBP (mmHg) & $120(23.08)$ \\
\hline $\mathrm{DBP}(\mathrm{mmHg})$ & $72(16.55)$ \\
\hline Temperature $\left({ }^{\circ} \mathrm{C}\right)$ & $37.2(0.69)$ \\
\hline Respiratory rate (/min) & $20(7.82)$ \\
\hline Pulse rate (/min) & $84(26.46)$ \\
\hline
\end{tabular}

\section{Discussion}

Hanging is not an uncommon mechanism of self-harm in our environment. It is more prevalent in men than in women and is often associated with the consumption of alcohol. ${ }^{[5]}$ There is a high prevalence of associated comorbidities among hanging victims, a significant need for emergency intubation (16.2\%) and admission to the ICU (4.5\%), and a $2.5 \%$ mortality rate. ${ }^{[5,6]}$ Self-inflicted hanging exerts prolonged pressure on the neck and may cause trauma to the cervical spine and aerodigestive tract, and global ischaemia of both cerebral hemispheres. ${ }^{[6]}$ In our series, hanging caused cervical spine injury in $6.4 \%$ of patients, and aerodigestive tract injury in $\sim 2.0 \%$. Our relatively high incidence of cervical spine injury is in keeping with the incidence reported from North American series. ${ }^{[7,8]}$ The high rate of cervical spine injury emphasises the importance of maintaining spinal immobilisation in these patients. ${ }^{[7,8]}$ Our incidence of laryngeal injury was $1.3 \%$, but a range of up to $5 \%$ of injuries to the larynx has been reported in the literature. These injuries are important because direct trauma to the soft tissue of the neck and to the larynx may result in airway compromise that will cause hypoxia, which may exacerbate the ischaemic insult to the brain. ${ }^{[3,4]}$ We did not identify any patients with a blunt carotid artery injury in our series, although the international literature suggests that there is a $1.5-2 \%$ incidence of this injury. Table 2 compares our data with the data from other reports on hanging.

Blunt injury to the carotid vessels is a rare but potentially serious injury. Sustained pressure on the carotid vessels may disrupt the intima of the artery, producing a highly thrombogenic surface that results in development of an unstable plaque that may occlude the artery or embolise into the cerebral circulation. Early detection of an intimal injury may allow for intervention. ${ }^{[7,8]}$ In view of the severity of the potential complications of blunt carotid artery injury, most centres, including our own, aggressively investigate the carotid vessels in these patients.

\section{Study limitations}

This study is limited by its retrospective nature and by a lack of mortuary data. Patients who die may be taken directly to the state mortuary and bypass our facility, leading to underestimation of hanging-associated mortality and the incidence of potentially lethal 


\section{Table 2. Comparison of studies on attempted hanging}

\begin{tabular}{|c|c|c|c|}
\hline & $\begin{array}{l}\text { Martin et al. }{ }^{[7]} 2005 \\
(N=655)\end{array}$ & $\begin{array}{l}\text { Salim et al. }{ }^{[8]} 2006 \\
(N=63)\end{array}$ & $\begin{array}{l}\text { Buitendag et al. (present study) } \\
(N=154)\end{array}$ \\
\hline Age (years), mean (SD) & $30.3(13.3)$ & $28(14)$ & 29.4 \\
\hline Sex male, $n(\%)$ & 84.1 & 87.3 & 84.4 \\
\hline SBP $(\mathrm{mmHg})$, mean (SD) & $115(56.3)$ & $123(41)$ & $120(23.08)$ \\
\hline \multicolumn{4}{|l|}{ GCS, $\%$} \\
\hline$>12$ & 23.0 & 60.3 & 76.0 \\
\hline $9-11$ & 7.0 & 7.9 & 9.1 \\
\hline$<9$ & 60.0 & 27.0 & 14.9 \\
\hline Missing data & 10.0 & 4.8 & 0 \\
\hline Mortality, \% & 33.0 & 9.5 & 2.5 \\
\hline \multicolumn{4}{|l|}{ CT findings, $\%$} \\
\hline Intracranial pathology & 41.0 & 12.7 & 27.0 \\
\hline Spinal pathology & 18.0 & 4.8 & 6.5 \\
\hline Laryngeal pathology & 5.0 & 4.8 & 1.3 \\
\hline Vascular pathology & 2.0 & 1.6 & 2.0 \\
\hline
\end{tabular}

injuries such as blunt carotid artery injury. We therefore continue to advocate a formal CT angiogram in these patients to exclude these relatively rare but potentially devastating and occult injuries. Further work should review mortuary data to determine the true incidence of blunt carotid artery injury in victims of hanging.

\section{Conclusions}

Hanging is a common mechanism of self-harm. It is associated with significant injuries and mortality. The acute management of hanging should focus on airway protection, followed by detailed imaging of the head and neck. Further work must attempt to include mortuary data on hanging.

\section{Declaration. None.}

Acknowledgements. None.

Author contributions. JJPB and DLC: writing of manuscript; JJPB, AR, RDW, JB: data and results management; GLL and JLB: upkeep of electronic registry; VYK and DLC: manuscript review and corrections.
Funding. None.

Conflicts of interest. None.

1. Hanna SJ. A study of 13 cases of near-hanging presenting to an accident and emergency department Injury 2004;35(3):253-256. https://doi.org/10.1016/S0020-1383(03)00110-4

Vande Krol L, Wolfe R. The emergency department management of near-hanging victims. J Emerg Med 1994;12(3):285-292. https://doi.org/10.1016/0736-4679(94)90268-2

3. McHugh TP, Stout M. Near-hanging injury. Ann Emerg Med 1983;12(12):774-776. https://doi, org/10.1016/S0196-0644(83)80256-X

Kaki A, Crosby ET, Lui AC. Airway and respiratory management following non-lethal hanging. Can Anaesth 1997;44(4):445-450. https://doi.org/10.1007/BF03014468

Kao CL, Hsu IL. Predictors of functional outcome after hanging injury. Chin J Traumatol 2018;21 (2):8487. https://doi.org/10.1016/j.cjtee.2017.04.013

6. Simonsen J. Patho-anatomic findings in neck structures in asphyxiation due to hanging: A survey of 80 cases. Forensic Sci Int 1988;38(1-2):83-91. https://doi.org/10.1016/0379-0738(88)90012-6

7. Martin MJ, Weng J, Demetriades D, Salim A. Patterns of injury and functional outcome after hanging: Analysis of the National Trauma Data Bank. Am J Surg 2005;190(6):836-840. https://doi. org/10.1016/j.amjsurg.2005.05.051

8. Salim A, Martin M, Sangthong B, Brown C, Rhee PM, Demetriades D. Near-hanging injuries: A 10. Salim A, Martin M, Sangthong B, Brown C, Rhee PM, Demetriades D. Near-hanging in
year experience. Injury 2006;37(5):435-439. https://doi.org/10.1016/jinjury.2005.12.013

Accepted 30 September 2019. 